\title{
Administrator urges penalties for doctors who don't use electronic medical records
}

$\mathrm{P}$ hysicians should be compelled by law to use electronic medical records (EMRs), one of Canada's leading health administrators says.

Moreover, doctors should face stiff consequences if they fail to do so, Tom Closson, president and CEO of the Ontario Hospital Association and a member of the board of directors of Canada Health Infoway, told a gathering of 1500 delegates attending the eHealth 2011 conference in Toronto, Ontario in June.

"Maybe some penalties for not becoming part of the modern world would be a good idea," Closson said, while arguing for legislation obligating doctors to adopt EMRs.

Estimating that just $25 \%$ of Canadian physicians use EMRs, Closson said the time has come to use extreme sanctions, including the firing of doctors who refuse to do so.

"I don't believe they should have any choice," he said during a plenary discussion on "Quality Improvement in Healthcare: An Executive's Perspective."

Closson's comments were offered within the context of a broader argument that deficiencies in the quality of health care services require reform to the delivery of primary care. "The biggest weakness we have is in primary care," he argued. "The part of the system where the public gets most of their care is totally opaque. ... We do not have any public reporting on primary care in this province."

Within that context, Closson said pay-for-performance structures should be imposed on doctors to help drive physicians to implement EMRs. "Changing the way they are paid changes the way they practise."

Paying physicians who do not use EMRs is an "unfair and inappropriate use of public money," Closson said, adding that the system cannot simply afford to wait for change in the form of the retirement of a generation of doctors.

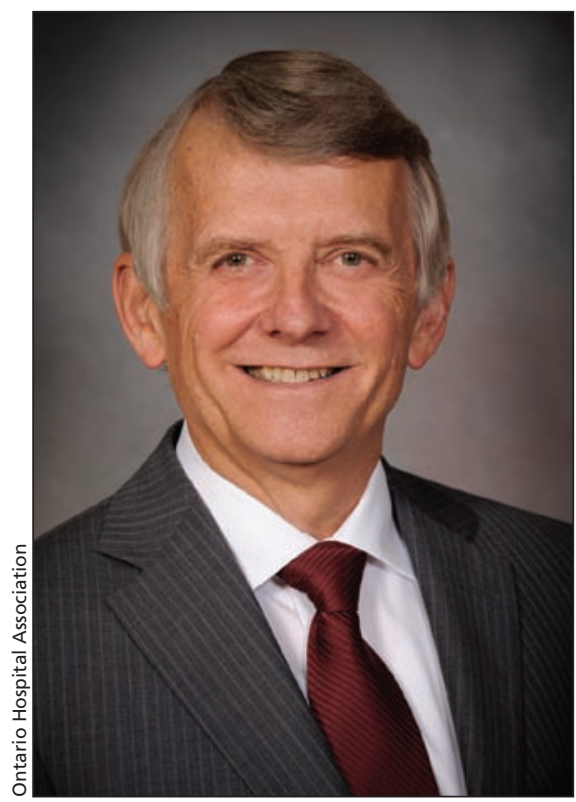

Some doctors prefer paper rather than electronic records but Ontario Hospital Association President and CEO Tom Closson says such doctors should not be given a choice. "Maybe some penalties for not becoming part of the modern world would be a good day," Closson says.

With many health care providers working into their seventies before retiring, the fact is that a lot of doctors who do not use EMRs will not be leaving soon, he said.

But the notion of mandatory physician use of EMRs did not sit well with all delegates.

Refashioning medical practice around new technologies is "very difficult" for many physicians and such professional change requires time and planning, said Dr. Chris Hayes, medical officer for the Canadian Patient Safety Institute.

While technology offers a path toward health reform, it is not "the Holy Grail" and change should be accomplished through professional development initiatives, not through bureaucratic fiat, he said. "It's not physicians versus the administration."

Others argued at the conference that the challenges are more systemic and that the need for EMRs in clinical practice is not as self-evident as many believe.

Physician training in the use of EMRs has not been adequate, while Canada Health Infoway and the provinces have invested heavily in information systems that are, for the most part, of little use to physicians and patients, said David Levine, president and executive director of the Montreal Regional Health and Social Services Agency in Quebec. "We tried to create monsters and nobody wanted to use them."

Levine also argued that legislative solutions aren't always appropriate; that medical students aren't being adequately prepared to utilize EMRs; and that physicians will resist being measured on the basis of EMR use.

Offering carrots, rather than a stick, is a more appropriate approach to increasing EMR utilization rates, Levine argued. "Leadership is the key" to encouraging physicians to adopt new technologies that may improve care.

At another plenary session, it was argued that increased use of EMRs would help ensure the financial sustainability of the Canadian health care system.

Jennifer Zelmer, Infoway's senior vice-president for clinical adoption and innovation, noted that primary care in Denmark and the United States involve more extensive use of information technologies for such things as "virtual consultations" to the benefit of patients.

But increasing the use of such virtual consultations within Canada will require changes in payment models for physicians, said Saäd Rafi, deputy minister of health and long-term care for Ontario.

"Provide an incentive for more primary care physicians to have virtual transactions and I am pretty sure they will use it," said Rafi, a member of Infoway's board of directors. - Paul Christopher Webster, Toronto, Ont.

CMAJ 2011. DOI:10.1503/cmaj.109-3914 